\title{
METHODS AND TOOLS FOR CONSTRAINT BASED INFORMATION INTEGRATION
}

\author{
Sven Kleiner and Reiner Anderl \\ Technical University Darmstadt \\ Department of Computer Integrated Design \\ kleiner@dik.tu-darmstadt.de
}

\begin{abstract}
An analysis of today's data exchange processes and product data integration technologies expose a lack of continuous computer aided methods during product development. This document outlines a new approach for the integration of product models based on constraints. A parametric product data model is presented which offers the possibility to link interdisciplinary product model structures and properties in order to allow interoperability among applications in design departments. A first software prototype illustrates the realized integration infrastructure and demonstrates the functionality of the constraint based information integration concept.
\end{abstract}

\section{INTRODUCTION}

The ever increasing pressure towards lower costs, shorter development cycles and more product quality requires the use of computer aided methods and software tools in engineering departments. Today, innovative products are complex and include mechanical, hydraulic, pneumatic, electric, controller, and even software components. From this it follows, that different CAx systems support engineering work.

In virtual product development processes, product models of the involved engineering domains are characterized by incomplete information and have to be modified many times within iterative processes. Provided that different CAx systems can have access to all relevant data and data can be kept consistent during engineering processes, design activities can be processed quicker and more adaptive according to customer's requirements and change requests. Therefore, the involved engineering domains, CAx systems, and partial product models need to be integrated in an environment, which supports necessary product model integration and data exchange. A new approach for the integration of product data models using constraints of product model parameters and structures is presented in order to enhance system integration and Concurrent Engineering. 


\section{TECHNOLOGIES OF INTEGRATION IN VIRTUAL PRODUCT DEVELOPMENT PROCESSES}

A holistic approach, which is based on integrating product development processes comprises a three-level-architecture (Gausemeier et al., 1999). The integration of processes, systems and models. The integration of processes means supporting engineering methods and work within departments, companies and co-operations as well as workflow management. The main objective of system integration is a spanning communication in CAx environments providing communication and network services. Model integration signifies that different tools using proprietary product data models are sharing data using a common data base or an integrated digital product master model. The result of model integration is a discipline overlapping product model. To limit the scope of a general product model, a number of special purpose models modularize the common product data model and are tailored to certain design aspects.

\subsection{Integration of Systems}

Regarding communications between engineering tools and sharing of engineering data the following system architectures are popular.

Firstly, tools are connected directly. This architecture implies one-to-one interfaces between tools using data access methods of provided application programming interfaces (API). APIs depend on software programs and software releases. Hence, operation and service of one-to-one interfaces is very expendable. Secondly, the interconnection of tools is indirect. The communication between engineering tools is supported by Product Data Management systems (PDM) using physical files or a data base. Last but not least, the continuing evolution of standards like CORBA (Common Object Request Broker Architecture) and the specified CAD services from the OMG (Object Management Group), the DCOM (Distributed Common Object Model) or .NET technologies from Microsoft will drive architectures to flexible integrated platforms in future, where software applications even in engineering domains will exchange product data in an active way.

\subsection{Integration of Product Models}

With the assistance of a common product data model, data mapping mechanism between product data models in CAx tools can be provided. For the integration of different model views a defined data model structure is crucial and entails efficient methods for data mapping between all interesting views. The idea of ISO 10303 STEP (Standard for the Exchange of Product Model Data) is based on a single, standardized product model, that captures and retrieves all relevant product data. But common neutral and standardized data models support geometric based engineering processes only. For example, ISO 10303-214 (STEP Application Protocol 214, AP 214) is used for data exchange between $C A D$ systems or between $C A D$ and FEA systems only. Furthermore, the missing of parametric, constraint-based, and featurebased model characteristics is a handicap of STEP AP's. The required relations between design and simulation models are not realized in any STEP AP until now. 


\section{INTEGRATION OF PRODUCT MODELS USING CONSTRAINTS AND REFERENCES}

\subsection{Interdisciplinary Constraints in Product Development}

Product models for design, analysis and simulation are usually built up parametrical and hierarchal in multiple ways by specific software packages for design (CAD), finite element analysis (FEA), multi body system simulation (MBS), controller design (CACD), etc. In order to define and analyse product attributes different product models such as design models, kinematic models, hydraulic models, electrical models, and system models are needed. The total number of the mentioned partial models in product development represent the holistic structure and characteristics of the intended product. The process of modeling is specific in each engineering discipline and the resulting product models are not connected tight enough to form an integrated digital master model. Nevertheless, properties of the mentioned product models need to be shared and differing product model structures must be comparable to each other (Anderl et. al, 2001).

Except for geometry based data transfers (e.g. CAD-FEA, CAD-MBS) there is neither exchange nor integration of product model data for interdisciplinary product development (e.g. design of mechatronic systems) available. Hence, a new approach has been researched, which links product models using constraints between parameters and model structures. The integration concept is based on parametric product models, which share their properties using constraints and are connected using logical links between model nodes.

Figure 1 shows the concept of interdisciplinary constraints representing relationships between product models.

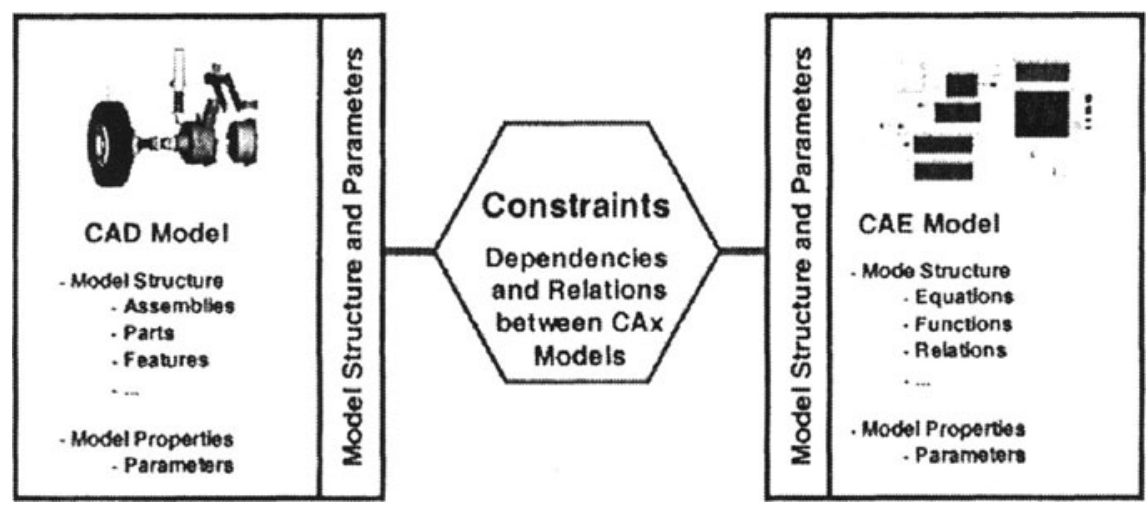

Figure 1: Interdisciplinary Constraints between Product Models

\subsection{A Framework for a Constraint Based Information Model}

The information model which integrates CAx models is the blueprint of a virtual product model and a repository for interdisciplinary knowledge. Concerning information modeling the paradigm of parametric is still in research. The short-term approach has already led to the definition of constraints in ISO 10303-50 (STEP Part 50) and parametrics ISO 10303-108 (STEP Part 108). Furthermore, the suggested 
approach can act as a framework for parametric in virtual product development. The defined information model is specified using the Unified Modeling Language (UML) and is based on the mentioned concepts of ISO10303 and parametrics.

The fundamentals for the development of neutral, parametric information structures for the integration of product models are provided by existing product data models or data models from ongoing research and development [Donges et al. 1999], [Gräb, 2001] as well as concepts from constraint logic programming [Frühwirt and Abdennadher, 1997]. The design of an extended, parametric information model could consider only few basic entities of STEP data models, for example units of functionality (UoF). The following information model containing parameters and constraints has been developed because standardization activities in the area of parametrics are still in work and are restricted on relations between geometrical information only.

Figure 2 illustrates the main classes and the structure of the developed parametric information model. The information model allows the integration of CAx models using interdisciplinary constraints restricting attributes of product model properties represented by scalar parameters, vectors, and matrices as well as model nodes represented by items, which are linked by interdisciplinary references.

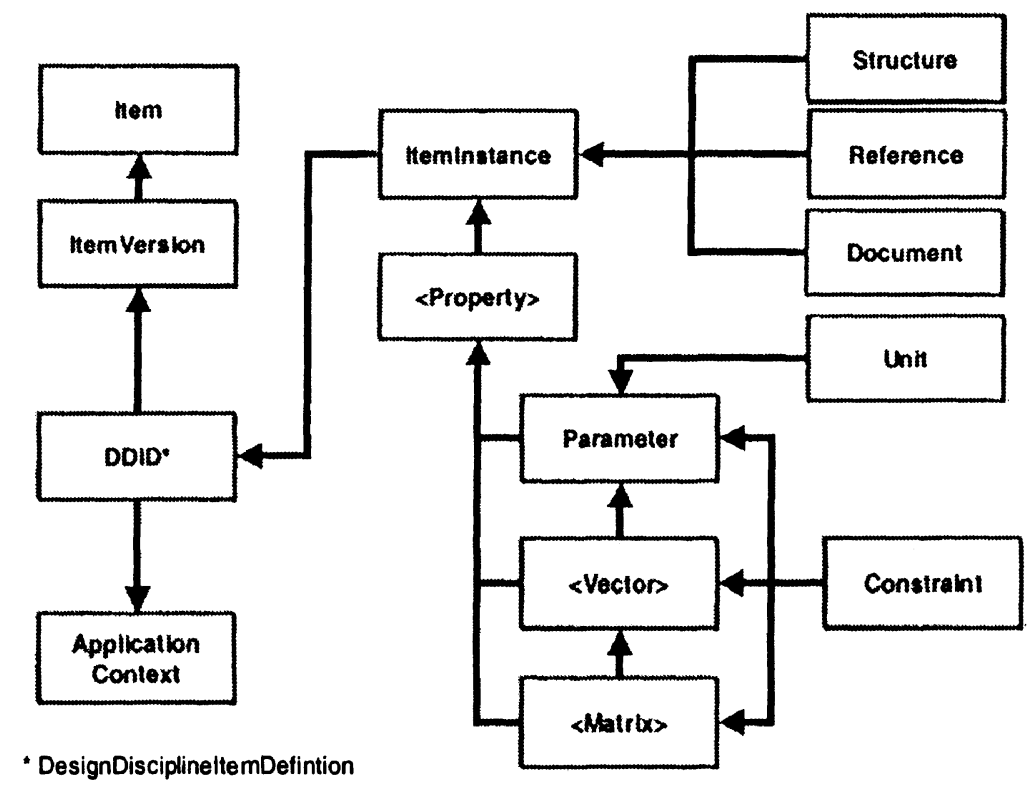

Figure 2: Schematic structure of the extended, parametric information model

The information model is containing the class Item, which represents real or virtual objects such as parts, assemblies, and models. Every object Item has a version (class ItemVersion) and specific views (class DesignDisciplineItem Defintion). A view is relevant for the requirements of one or more life cycle stages and application domains and collects product data of the Item and ItemVersion object. The extension of STEP product data models considers the inclusion of general product characteristics (class Property), attributes (class Parameter) and restricted relationships (class Constraint and Reference). The developed information model is based on the integration of independent CAx models using its structures 
and properties. The links between CAx models are implemented using the classes Constraint and Reference, which can set properties or structures of different product models in relationship to each other.

\subsection{A Realization of the Constraint Based Integration Concept}

Using the Java programming language, the information model and necessary methods are implemented in a software prototype which is called X-Portal. The XPortal enables the management and the exchange of structures and parameters of CAx models.

The software system links different CAx systems (e.g. CAD system CAE system) and imports and exports product data of CAx models, which are stored in a PDM system. The architecture of the X-Portal is illustrated in figure 3. The main components of X-Portal are

- a neutral product data model based on ISO 10303 (STEP) and extended by parametrics (data representation schema),

- interface components to CAx Systems (CAx Connectors) and a PDM System,

- a graphical user interface for the analysis and synthesis of CAx models and interaction.

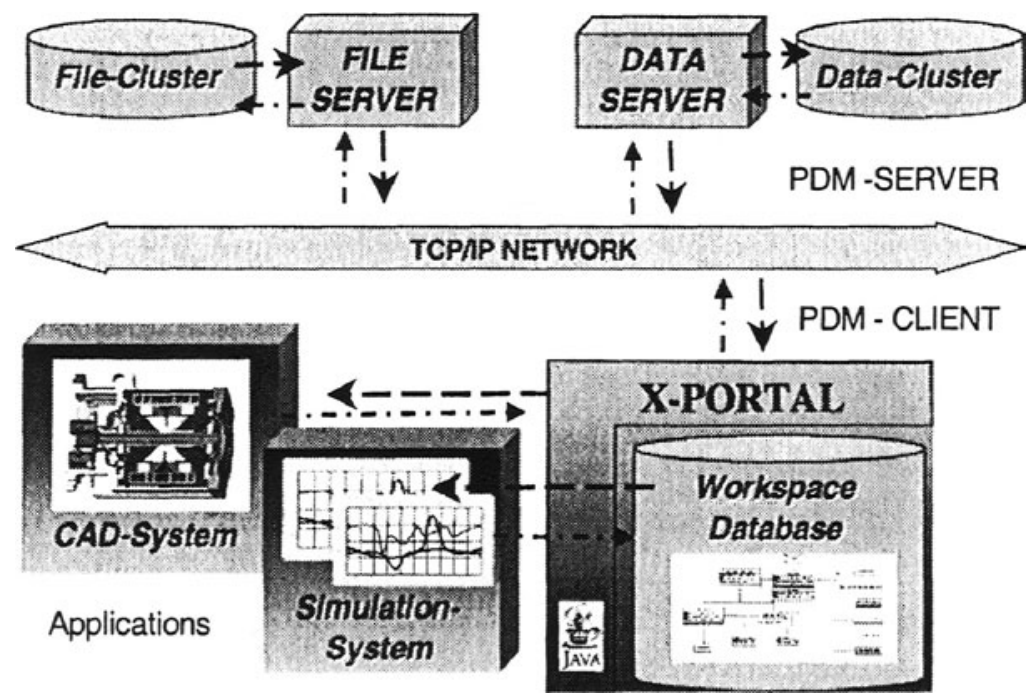

Figure 3: System Architecture of X-Portal

The X-Portal is based on conventional methods for data exchange and on new concepts for the integration of parametric product data. The management of CAx models and data exchange between different application systems are supported by linking directly CAx systems as well as using import and export functions based on XML. In order to link product models and support data exchange between different CAx models, parallel representations of different model structure trees were implemented. Different views on product models, for example function structure view, product structure view, simulation model structure view, enable an interdisciplinary modeling process under consideration of specific conditions and 
requests of users. Relations and constraints between model structure trees and properties can be defined using simple "drag and drop" mechanisms.

Figure 4 shows how the X-Portal shall be used during product development. The mode of operation in principle can be described as follows: The X-Portal starts up a connection between different CAx systems (e.g. CAD system Pro/Engineer, CAE system Matlab/Simulink). Subsequently, those CAx models are loaded into the $\mathrm{X}$ Portal, which are needed for modeling reasons and serve as data sources. The user identifies the relevant data in accordance with his specification regarding data provision. Data provision and data preparation are supported by a defined disciplinespreading function structure, which facilitates the access to unknown model information. Last but not least, the identified model data are transferred to a target system (e.g. CAE system Matlab/Simulink) or exported into a digital file for further data processing.

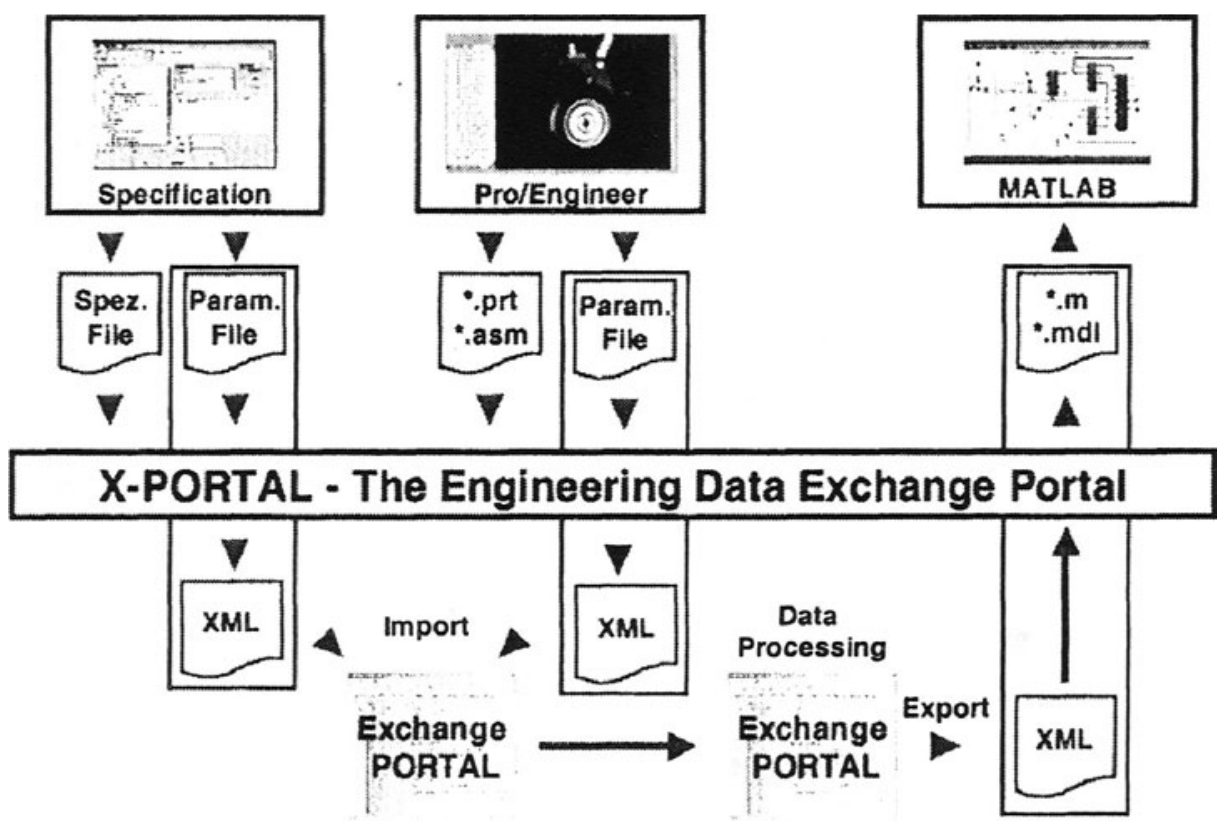

Figure 4: Data Processing during Product Development supported by X-Portal

For the determination of correlations between CAx models, the definition of a neutral system structure (e.g. function structure of the intended product) is important, which sets the models and model items (nodes) in relationship to each other. The application of system structure operations permit the representation, analysis, and synthesis of relations between different model structures, such as CAD (structure of building and assembly) or CAE (structure of physical and mathematical behavior). The system structure indicates references between CAx model nodes and serves as an integrative structure for interdisciplinary modeling in design, computation, and simulation. It was shown that this methodology particularly meet the need of developers, since the spreading use of a system structure supports the working method of engineers from any domain.

Figure 5 shows the graphical user interface of the X-Portal. The panels represent different product models and model nodes (Structure Browser Panel) as well as model properties (General Property Panel) using views defined by application 
contexts. Relations between model structures and model transformations can be executed using context menus and mouse operations.

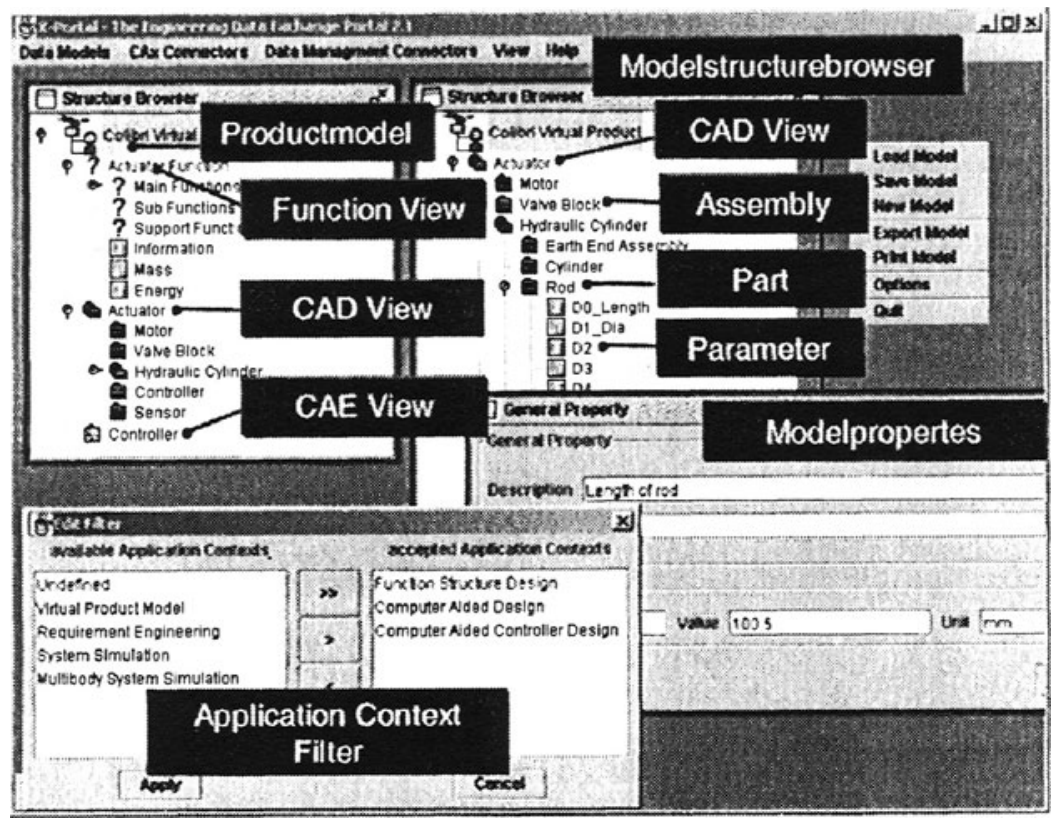

Figure 5: Screenshot of X-Portal

\section{ENGINEERING OF MECHATRONICS PRODUCTS SUPPORTED BY X-PORTAL}

In the following, the development of an integrated wheel suspension of an innovative service vehicle will be described as a use case scenario in order to show how mechatronic product development could be supported by X-Portal.

The development of an integrated wheel suspension was originally motivated by a research project (Anderl et al., 2000). In this project, a vehicle for the distribution of goods in cities has been designed in order to check interactions between different engineering disciplines during the product development process. The final physical DMU of the service vehicle is illustrated in figure 6 .

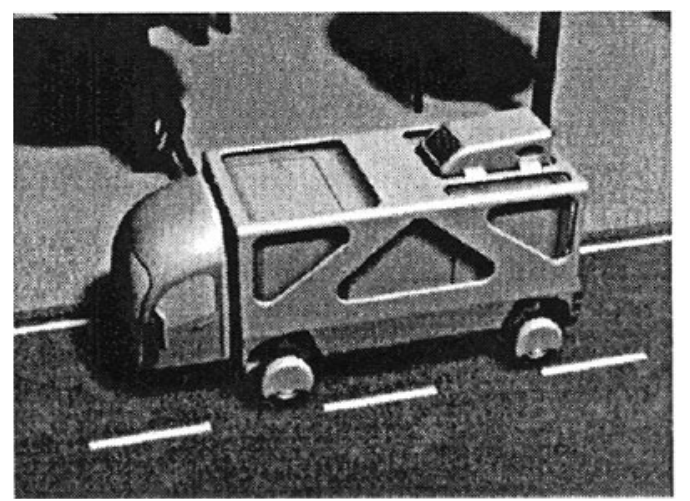

Figure 6: DMU of the innovative service vehicle 
New engineering design methods for mechatronic products as well as CAx systems were used during development and optimisation without having any hardware prototype of the wheel suspension in early design stages. Students of mechanical engineering, industrial engineering, and electrical engineering were involved to support researchers during design of selected vehicle components and optimisation of system behaviour, for example vertical dynamics of the vehicle. One specific task was to design the structure and shape of passive components of the active wheel suspension using a $\mathrm{CAD}$ system and to model and to analyze dynamical system behavior of passive components using CAE systems.

Parametric CAD models of the wheel module have been designed with the CAD system Pro/ENGINEER and the dynamics of the passive wheel module have been investigated using MATLAB/Simulink. The X-Portal supported the virtual product development according to design methodology and the mentioned constraint based integration concept (Kleiner and Anderl, 2002). Further, it was used to extract geometrical, functional, and dynamical parameters from CAx models and to link them to parameters of other CAx models in order to keep data consistent across the domain specific product models. X-Portal imported and exported data in order to set up and parameterize models for dynamic system simulation in MATLAB/Simulink.

\section{FINDINGS}

The conception of an extended parametric product data model and the implementation of the software prototype X-Portal have validated a new approach of constraint based product data integration. It is possible to integrate different CAx models by linking model properties and structures using constraints and references in order to specify their relationships for product development reasons. In addition, it is important to incorporate PDM functions such as version, configuration, and change management for the management and data exchange of product models in the next releases of X-Portal for its application in the entire product life cycle.

\section{REFERENCES}

1. Anderl, R. et al. "Computer Aided Design of Mechatronic Systems exemplified by the Integrated Wheel Suspension of an Innovative Service Vehicle“. Proceedings of the 1st IFAC-Conference on Mechatronic Systems, VDI-Verlag, Düsseldorf, Germany, 2000.

2. Anderl, Reiner, Gräb, Robert, Kleiner, Sven. „Integration parametrischer Produktdaten als Grundlage der virtuellen Produktentwicklung“. In Industrie Management 3/2001, GITO, 2001, pp 76-80.

3. Anderl, Reiner, Kleiner, Sven. „Interdisciplinary Methods and Tools for the Design of Mechatronic Products". In Proceedings of the Design 2002. 7th International Design Conference, May 14-17, 2002. Dubrovnik, Croatia. pp. 515-520.

4. Donges, Christian, Krastel, Marcus, Anderl, Reiner. „MechaSTEP - STEP Datenmodelle zur Abbildung mechatronischer Systeme“. In Produktdatenjournal Nr. 1/1999, ProSTEP, 1999, pp. 3034.

5. Frühwirt, T., Abdennadher, S. Constraint-Programmierung. Berlin, Springer, 1997.

6. Gausemeier, J., Grasmann, M., Kespohl, H.-D.. „Verfahren zur Integration von Gestaltungs- und Berechnungssystemen“. In VDI Berichte Nr. 1487, VDI, 1999, pp. 71-87.

7. Gräb, Robert. Parametrische Integration von Produktmodellen für die Entwicklung mechatronischer Produkte. Aachen, Shaker, 2001. 